\title{
Design and development of a segmented rubber tracked vehicle for Sepang peat terrain in Malaysia
}

\begin{abstract}
In order to improve the crossing ability, the tractive performance of a vehicle operating on low bearing capacity peat terrain and the loss of income resulting from downtime and maintenance cost, the vehicle must be designed with an ability to adapt to the changes of prevailing operation conditions. This paper describes the design and development of a new segmented rubber tracked vehicle for peat terrain in Malaysia. A new mathematical model for peat terrain, which was used to determine the forces at the ground contact parts of the track element of front idler-terrain, intermediate roadwheels-terrain, and rear sprocket-terrain interfaces is developed. The simulated performance results, such as vehicle average motion resistance coefficient of $6.8-7.9 \%$, drawbar pull coefficient of $25.22-47 \%$, and the tractive efficiency of $74-77 \%$ for the vehicle slippage of 5-20\% indicate that the vehicle can meet the peat terrain field requirement with its optimal power consumption. Copyright (C) 2005 Inderscience Enterprises Ltd.
\end{abstract}

Keyword: Mathematical model; Peat terrain; Track vehicle; Tractive performance 